\title{
Perencanaan lanskap wisata kesehatan di pesisir Desa Kusamba, Kecamatan Dawan, Kabupaten Klungkung
}

\author{
Komang Indah Tri Raheni ${ }^{1}$, Lury Sevita Yusiana ${ }^{1 *}$, Ni Wayan Febriana Utami ${ }^{1}$ \\ 1. Prodi Arsitektur Pertamanan, Fakultas Pertanian, Universitas Udayana, Indonesia 80232i
}

*E-mail: lury.yusiana@unud.ac.id

\begin{abstract}
Health tourism landscape planning in coastal Kusamba, Kusamba Village, Dawan sub-district, Klungkung Regency. Kusamba village is a village in eastern Klungkung that has coastal potential as a tourist destination. Kusamba coastal is famous for its marine products and traditional salt making, unfortunately that traditional salt making now lost it's existence. Kusamba coastal also has the potential of nature that can be utilized as a health tourism using sea salt and black sand. The purpose of this study was to plan the existing landscape of the Kusamba coastal and to preserved natural products and traditional salt making. Method used in this study was field survey with observation technique, interview, distributing questionnaire, and literature study. The planning method applied was implemented Simonds planning process (2006) with some modification. The results showed that tourism activities and health tourism applied in coastal areas of Kusamba were salt spa and black sand therapy where is the visitors can relaxed their body with sea salt and black sands. It can be recommended that further research on development of nature tourism Kusamba need to held in order to explore Kusamba have coastal forest which is very potential as nature tourism.

Keywords: health tourism, landscape planning, landscape tourism, Kusamba Village,
\end{abstract}

1. Pendahuluan

Kabupaten Klungkung adalah kabupaten terkecil di Provinsi Bali. Ibukotanya berada di Semarapura. Klungkung berbatasan dengan Kabupaten Bangli di sebelah Utara, Kabupaten Karangasem di Timur, Kabupaten Gianyar di Barat dan dengan Samudra Hindia di sebelah Selatan. Sepertiga wilayah Kabupaten Klungkung $\left( \pm 112,16 \mathrm{~km}^{2}\right)$ terletak di pulau Bali dan dua pertiganya $\left( \pm 202,84 \mathrm{~km}^{2}\right)$ lagi merupakan kepulauan, yaitu Nusa Penida, Nusa Lembongan dan Nusa Ceningan. Kabupaten Klungkung memiliki pantai dengan Panjang garis pantai yaitu $\pm 90 \mathrm{~km}$ terdiri atas $\pm 20 \mathrm{~km}$ berada di Klungkung daratan dan $\pm 70 \mathrm{~km}$ berada di Klungkung kepulauan. Salah satu pantai di kabupaten Klungkung yaitu pantai Kusamba. Pantai Kusamba adalah pantai yang terletak di Desa Kusamba, Kecamatan Dawan, Kabupaten Klungkung yang memiliki panjang garis pantai $\pm 1,65 \mathrm{~km}$. Lokasi ini disebut dengan Pantai Kusamba dikarenakan pantai ini berada di sebuah Desa yang bernama Desa Kusamba. Pantai kusamba selalu ramai oleh orang-orang yang mencari nafkah mulai dari nelayan, buruh, petani hingga pencari batu. Semua hal yang dikerjakan masih menggunakan cara-cara tradisional. Misalnya, para nelayan dan petani garam di Kusamba masih menggunakan cara tradisional dalam hal melaut mencari ikan dan menghasilkan garam, oleh karena itu, dengan berkembangnya Pariwisata di Bali yang sudah semakin pesat menjadikan obyek wisata tradisional ini perlu dijaga. Kelestarian obyek wisata tersebut dapat terjaga dengan menerapkan perencanaan lansekap wisata berbasis daya dukung kawasan dengan penataan kawasan sebagai kawasan wisata rekreasi dan kesehatan. Sehingga perencanaan lanskap wisata kesehatan di pesisir Kusamba dilakukan untuk menjaga budaya penggaraman tradisional sebagai kawasan wisata serta memanfaatkan komoditi garam kusamba. Berdasarkan latar belakang tersebut, maka dapat dirumuskan beberapa tujuan dari penelitian ini yaitu untuk menginventarisasi potensi wisata yang ada di pesisir Kusamba dan untuk merencanakan kawasan pesisir Kusamba sebagai lanskap wisata kesehatan. Manfaat yang didapatkan dalam penelitian ini adalah untuk melestarikan lansekap pesisir khususnya penggaraman tradisional di Kusamba Klungkung dan dapat menambah pengetahuan dan wawasan menganai pesisir Kusamba. 
2. Metode

\subsection{Waktu dan Lokasi Penelitian}

Penelitian ini dilakukan di wilayah pesisir pantai Kusamba Kabupaten Klungkung,Provinsi Bali pada bulan Maret sampai dengan Mei 2017. Penelitian dimulai dari Pelabuhan Tribhuwana sampai Pantai Pesinggahan. (Gambar 1)

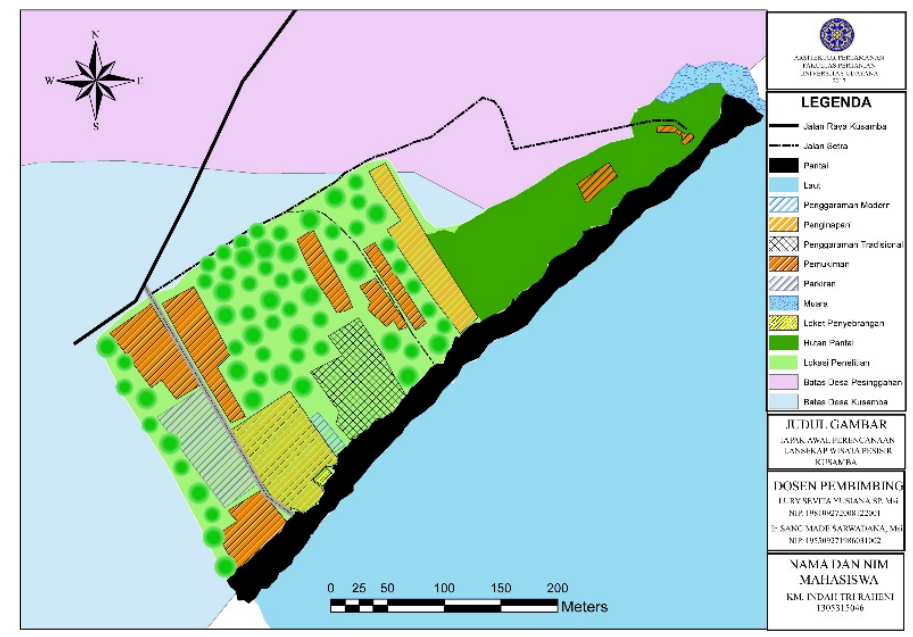

Gambar 1. Lokasi Penelitian

\subsection{Alat dan bahan Penelitian}

Alat dan bahan yang digunakan dalam penelitian ini adalah lembar pertanyaan wawancara, lembar kuisioner, alat ukur, kertas dan pensil, kamera, laptop dengan software berupa AutoCAD 2013, adobe Photoshop CS4 dan peta dari Google Earth.

\subsection{Data Penelitian}

Jenis data yang dikumpulkan dalam penelitian ini berupa data primer dan data sekunder. Data primer diperoleh melalui hasil pengamatan langsung di lapangan dengan melakukan observasi, wawancara dan penyebaan kuesioner. Data sekunder berupa pengumpulan data yang diperoleh dari studi pustaka, yaitu yang bersumber dari jurnal kesehatan dan jurnal pariwisata serta data dari BPS Kabupaten Klungkung.

Metode pengumpulan data yang digunakan meliputi observasi lapang, wawancara, penyebaran kuesioner dan studi pustaka.

\subsection{Metode Penelitian}

Metode penelitian perencanaan lansekap kawasan pesisir pantai Kusamba menggunakan metode survey yang mengacu pada tahapan proses perencanaan Simonds (2006) dengan penyesuasian atau modifikasi yang meliputi beberapa tahapan yaitu pogram pengembangan, pemilihan tapak, analisis tapak, perencanaan tapak komprehensif, pedoman analisis tapak, rencana konseptual dan perencanaan tapak. Lokasi penelitian dilakukan di kawasan Pesisir Tribhuwana Desa Kusamba, Kecamatan Dawan, Kabupaten Klungkung, Bali. Penelitian ini dilakukan sampai tahap perencanaan. Hasil berupa siteplan dan gambar ilustrasi.

\section{Hasil dan Pembahasan}

\subsection{Gambaran Umum Lokasi Penelitian}

Tapak yang direncanakan terletak di pesisir Pelabuhan Tribhuwana Desa Kusamba, Kecamatan Dawan, Kabupaten Klungkung, Provinsi Bali. Secara geografis terletak pada $8^{\circ} 33^{\prime} 48,24$ "LS s/d $115^{\circ} 27^{\prime} 06.78^{\prime \prime B T}$. Desa Kusamba merupakan salah satu Desa dari 12 Desa yang ada di Kecamatan Dawan dengan luas wilayah mencapai $242 \mathrm{Ha}$. Desa Kusamba merupakan salah satu desa yang berada di daerah pesisir pantai yang memiliki jumlah penduduk 7.491 jiwa dengan jumlah kepala keluarga (KK) berjumlah 1.917 KK (Profil Desa Kusamba, 2016), yang sudah barang tentu kehidupan masyarakatnya bergantung pada hasil laut. Dalam memenuhi kehidupan sehari harinya penduduk Desa Kusamba mempunyai 
mata pencaharian sebagi Nelayan, disamping juga sebagai petani yang menjadi andalan penghasilan masyarakat di Desa Kusamba bilamana terjadi musim paceklik dilaut.

\subsection{Program Pengembangan}

Pesisir Kusamba merupakan salah satu potensi wisata yang ada di Desa Kusamba yang cukup ramai dikunjungi. Pesisir Kusamba memiliki sesuatu yang unik yaitu penggaraman yang masih menggunakan cara tradisional, akan tetapi penggaraman tersebut semakin berkurang keberadaannya. Menurut Mangku Rena, ketua kelompok petani garam di Desa Kusamba, terdapat 17 petani garam di sepanjang pesisir Kusamba akan tetapi adanya abrasi berdampak pada keberlangsungan pertanian garam karena lahan untuk bertani garam menjadi berkurang .Berdasarkan tujuan dari perencanaan lanskap wisata di Pesisir Kusamba program pengembangan perencanaan lanskap wisata di Pesisir Kusamba meliputi: 1. Melestarikan penggaraman tradisional dengan membantu para petani garam memperoleh pendapatan lain dengan di kembangkannya pesisir kusamba sebagai daya tarik wisata. 2. Memberi peluang usaha bagi masyarakat lokal melalui pengembangan wisata kesehatan di pesisir kusamba.

\subsection{Pemilihan Tapak}

Penggaraman tradisional mulai ditinggalkan karena hasil yang didapatkan dirasa tidak cukup untuk memenuhi kebutuhan sehari-hari serta tidak adanya penerus untuk meneruskan penggaraman tradisional maka dari itu petani-petani garam mulai mencari pekerjaan lainnya yang lebih menjanjikan dan hanya tersisa beberapa petani garam. Penggaraman tradisional sudah seharusnya di lestarikan dengan menjadikannya suatu objek wisata yang terencana.

Pesisir Kusamba cukup sesuai untuk dijadikan Daerah Tujuan Wisata (DTW) dan kesehatan karena terdapat beberapa hal yang dapat dilakukan seperti mengunjungi penggaraman tradisional serta terapi pasir hitam dan juga melakukan spa garam tradisional di sepanjang pesisir kusamba.

\subsection{Analisis dan Sintesis Tapak \\ 3.4.1 Analisis Biofisik}

$\underline{\mathrm{klim}}$

Desa Kusamba merupakan desa pesisir, desa kusamba memiliki suhu dengan tinggi $27^{\circ} \mathrm{C}$ dengan curah hujan $1539 \mathrm{~mm}$ per tahun. Kriteria musim yang harus dipenuhi pada saat produksi garam menurut Hernanto dan Kwartatmono (2001) adalah curah hujan rendah (1000-1400 mm/tahun). Curah hujan di Kecamatan Dawan sebesar $1539 \mathrm{~mm} / \mathrm{tahun}$ dan memengaruhi pembuatan garam karena rentang $\mathrm{CH}$ yang dibutuhkan untuk menghasilkan garam berkisar antara 1000-1400 mm/tahun. Curah hujan yang tinggi mengakibatkan gagalnya pengkristalan garam.

Vegetasi dan Satwa

Berdasarkan pengamatan jenis vegetasi tanaman yang terdapat di lingkungan pesisir Kusamba yaitu tanaman yang memang hidup di pesisir pantai yang dapat dikatakan sebagai hutan pantai. Pada hutan ini dijumpai jenis vegetasi dengan formasi Barringtonia dan Pescaprae (Tabel 1).

Tabel 1. Vegetasi Pesisir Kusamba

\begin{tabular}{ccc}
\hline Lokasi & Nama Lokal & Nama Ilmiah \\
\hline Formasi Barringtonia & Butun & Barringtonia asiatica \\
& Waru & Hibiscus tiliaceus \\
& Ketapang & Terminalia catappa \\
& Biduri & Calotropis gigantean \\
& Katang-katang & Ipomoea pescaprae \\
& Spinefex & Spinifex littoreus \\
& Pandan duri & Pandanus tectorius \\
& Gamal & Pandanus tectorius \\
Formasi pescaprae & Kelapa & Cocos nucifera \\
& Pandan duri & Pandanus tectorius \\
\hline
\end{tabular}


Lanjutan tabel 1.

\begin{tabular}{ccc}
\hline Lokasi & Nama Lokal & Nama Ilmiah \\
\hline Formasi Pescaprae & Gamal & Gliricidia sepium \\
& Kelapa & Cocos nucifera \\
\hline
\end{tabular}

Selain itu, di sekitar lokasi penelitian juga dijumpai beberapa jenis hewan liar seperti anjing, ayam dan burung diantaranya dapat dilihat pada tabel 2.

Tabel 2. Satwa yang terdapat di pesisir Kusamba

\begin{tabular}{ccc}
\hline No & Nama Lokal & Nama llmiah \\
\hline 1. & Anjing & Canis lupus familiaris \\
2. & Ayam & Gallus gallus domesticus \\
3. & Burung & Aves \\
\hline
\end{tabular}

$\underline{\text { Fasilitas }}$

Untuk aksesibilitas pada kawasan, pesisir Kusamba merupakan daerah pesisir yang digunakan sebagai pelabuhan rakyat salah satunya di pesisir Tribhuwana maka dari itu banyaknya kendaraan yang keluar masuk lingkungan pelabuhan. Jalan utama menuju ke pelabuhan Tribhuwana cukup lebar akan tetapi hanya dapat dilewati oleh satu kendaraan roda empat saja. Sedangkan aksesibilitas jalan yang di lewati tidak terlalu sulit, kondisi jalan juga cukup bagus, lokasi pantai Kusamba ini sangat strategis karena tidak jauh dari pusat Kota Denpasar. Jarak yang ditempuh dari Denpasar ke lokasi yaitu kurang lebih 60 menit perjalanan melewati bypass Ida Bagus Mantra, sedangkan jarak ke pusat Kota Klungkung yaitu kurang lebih 20 menit.

Parkir di area pelabuhan Tribhuwana yang terletak di sebelah kanan pintu masuk sangat luas yaitu $4000 \mathrm{~m}^{2}$. Kapasitas mobil yang dapat ditampung kurang lebih mencapai 50 mobil dan tertata dengan rapi. Parkir sepeda motor juga di siapkan dengan kapasitas tampung lumayan besar kurang lebih dapat menampung 200 sepeda motor.

\subsubsection{Sosial Ekonomi Masyarakat Nelayan}

Desa kusamba terkenal dengan kegiatan melaut dari nelayan-nelayan yang masih menggunakan perahu kecil yang dinamakan jukung, tetapi seiring berkembangnya zaman banyak diantara nelayan-nelayan di Pesisir Kusamba beralih profesi para nelayan menjual perahu mereka yang setiap harinya digunakan untuk melaut karena menurut mereka melaut sudah tidak bisa untuk mencukupi kehidupan mereka karena hasil tangkapan yang sepi.

\subsubsection{Analisis Potensi Wisata}

View

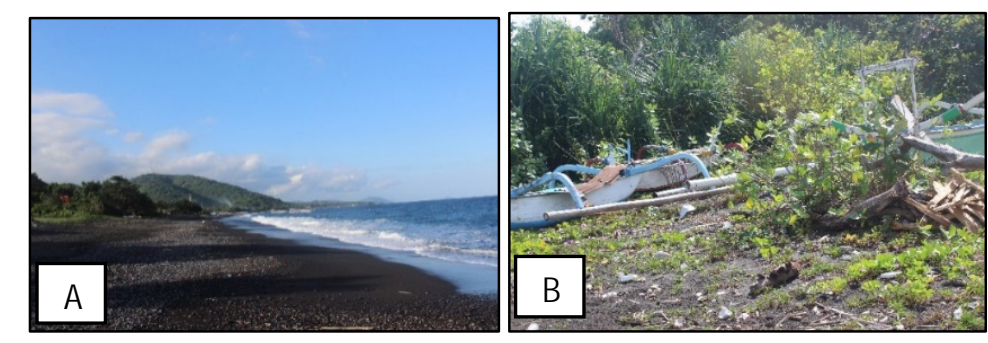

Gambar 2. Pemandangan Pesisir Pantai Kusamba (Dokumentasi Pribadi)

Keterangan: A: Pemandangan Yang Terlihat Di Pesisir Pantai Kusamba

B: Jukung

\section{Penggaraman Tradisional}

Penggaraman tradisional di pesisir Kusamba sudah sangat terkenal ke manca Negara, akan tetapi tidak banyak wisatawan yang berkunjung. Hasil wawancara dengan petani garam, dalam sekali panen garam yang dihasilkan sebanyak $15 \mathrm{~kg}$ garam basah yang menyusut menjadi $5 \mathrm{~kg}$ garam kering. 


\section{$\underline{\text { Pasir Hitam }}$}

Sepanjang pesisir Kusamba terdapat hamparan pasir hitam yang luas. Pasir hitam di pesisir Kusamba belum termanfaatkan secara optimal. Pasir hitam dengan hawa panas pasir $45-50^{\circ} \mathrm{C}$ dapat dijadikan alternatif terapi kesehatan. Terapi itu dapat dilakukan dengan cara berendam di galian pasir maksimal sedalam 0,5 meter, mulai pagi pukul 09.00 WITA sampai sore pukul 17.00 WITA. Waktu yang diperlukan untuk berendam di pasir juga tidak perlu terlalu lama, cukup hanya 15 menit (Dharma, 2018).

\subsection{Perencanaan Tapak Komprehensif}

Pesisir Kusamba memiliki potensi-potensi yang dapat dikembangkan sebagai lanskap wisata kesehatan karena selain berwisata melihat-lihat pembuatan garam dan sekedar berekreasi Pesisir Kusamba juga dapat digunakan sebagai tempat relaksasi tradisional seperti terapi pasir pantai dan terapi garam. Pesisir Tribhuwana Kusamba sangat cocok dijadikan sarana untuk wisata kesehatan karena terdapat penggaraman tradisional serta hamparan pasir hitam yang luas.

\subsection{Rencana Konseptual}

Rencana konsep yang akan diterapkan adalah "Eksplorasi dan Relaksasi Pantai". Desa Kusamba memiliki beberapa tempat yang dapat dijadikan DTW, sesuai dengan konsep Eksplorasi dan Relaksasi Pantai tentunya tempat-tempat yang akan dikunjungi berhubungan dengan mengeksplorasi pantai dan laut mulai dari hasil tangkapan nelayan sampai olahannya.

\subsubsection{Konsep Dasar}

Konsep dasar yang akan diterapkan yaitu wisata kesehatan pantai dimana pengunjung dapat memanfaatkan pasir hitam serta garam tradisional sebagai alternatif pengobatan tradisional dan tempat untuk merelaksasikan diri.

\subsubsection{Konsep Pengembangan}

DTW yang akan dikembangkan pada Pesisir Kusamba adalah DTW yang mampu menjadi tempat rekreasi sekaligus tempat untuk merelaksasikan tubuh. Konsep yang akan dikembangkan yaitu konsep wisata kesehatan yang menggunakan hasil dari pesisir Kusamba seperti garam laut dan juga pasir hitam.

\section{Konsep Tata Ruang}

Perencanaan tata ruang dibagi menjadi beberapa ruang yaitu ruang penerimaan, ruang aktifitas dan ruang inti. Penjabaran dari masing-masing zona yang direncanakan adalah: 1) Ruang penerimaan, yaitu ruang penerimaan merupakan ruang awal yang ditemui pengunjung saat memasuki DTW Pesisir Kusamba. Ruang ini berfungsi sebagai ruang penerimaan pengunjung mulai dari parkir sampai pusat informasi; 2) Ruang pelayanan, yaitu ruang pelayanan merupakan ruang yang dapat digunakan sebagai ruang kebutuhan berbagai fasilitas yang diinginkan wisatawan seperti pusat kuliner dan oleh-oleh; 3) Ruang inti, yaitu ruang inti merupakan ruang yang menjadi pusat dari kegiatan ekowisata. Ruang inti dibagi menjadi dua yaitu ruang wisata utama dan ruang wisata pendukung.

\section{Konsep Sirkulasi}

Sirkulasi pada DTW Pesisir Kusamba mengadopsi pola sirkulasi linear dimana sirkulasi mengikuti satu garis yang sama yang mengarah ke satu tujuan sehingga hanya terdapat satu akses masuk jalan menuju ke DTW.

\section{Konsep Vegetasi}

Vegetasi yang digunakan dalam konsep vegetasi perencanaan lanskap wisata di Pesisir Kusamba yaitu vegetasi yang memberi kenyamanan bagi pengunjung seperti tanaman peneduh agar aktivitas pengunjung pada siang hari tidak terganggu suhu yang tinggi. Penempatan tanaman peneduh tersebut pada tempat-tempat yang diperlukan seperti parkir dan di pinggiran dek kayu di sepanjang pesisir.

\subsection{Perencanaan Tapak}

Perencanaan tapak dengan konsep yang akan diterapkan pada tapak yaitu "Eksplorasi dan Relaksasi Pantai". Perencanaan wisata pada tapak akan dibagi menjadi dua bagian yaitu wisata utama dan wisata pendukung. Wisata utama yaitu kegiatan wisata yang berkaitan dengan tujuan utama yaitu berbagai terapi yang terdapat di pesisir Kusamba yang memanfaatkan bahan-bahan alami dari pesisir Kusamba. Wisata pendukung yaitu kegiatan wisata lainnya yang dapat dilakukan selain terapi kesehatan yaitu melihat-lihat pembuatan kapal, berfoto dan sekedar menikmati pemandangan laut.

\subsubsection{Rencana Tata Ruang}




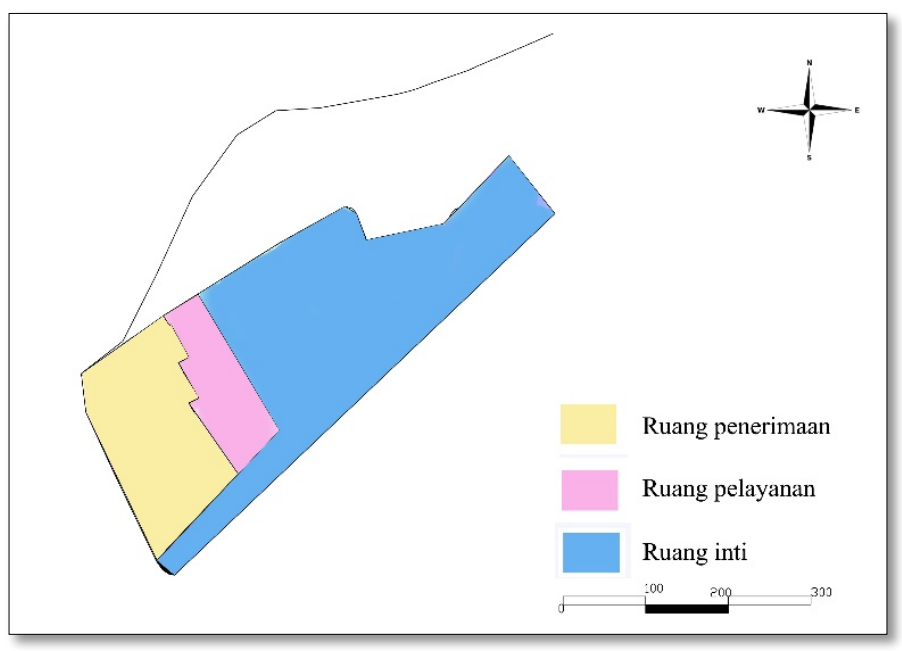

Gambar 3. Rencana Tata Ruang

\section{Ruang Penerimaan}

Pengunjung akan memasuki lahan parkir terlebih dahulu setelah itu pengunjung akan melihat pusat informasi sehingga pengunjung dapat bertanya-tanya mengenai pesisir kusamba dari penggaraman tradisional hingga berwisata kesehatan.

\section{Ruang Pelayanan}

Wisatawan akan memasuki ruang pelayanan setelah melewati pusat infromasi. Wisatawan dapat melihat-lihat cindera mata untuk dijadikan oleh-oleh. Oleh-oleh yang disediakan yaitu berbagai ciri khas Desa Kusamba. Pusat kuliner juga disediakan di ruang pelayanan, makanan yang disediakan yaitu makananmakanan khas Desa Kusamba maupun Kabupaten Klungkung.

Ruang Inti

Atraksi-atraksi yang akan di dikembangkan di ruang inti wisata utaman yaitu: 1) Aktivitas penggaraman tradisional, kegiatan mulai dari melihat-lihat cara pembuatan garam tradisional sampai ikut berpartisipasi dalam pembuatan garam seperti menyiramkan air laut, mengumpulkan pasir, menjemur bakal garam hingga memanen garam; 2) Berendam dalam air garam laut, kegiatan ini dimulai dengan berendam di dalam air hangat bercampur garam laut yang dapat merelaksasikan tubuh selain berendam di dalam larutan garam wisataan juga dapat mencoba masker dari garam laut; 3) Menimbun Badan di Dalam Pasir, pasir di pesisir Kusamba merupakan pasir bewarna hitam dan dapat dimanfaatkan sebagai sarana kesehatan. Pengunjung dapat melakukan tanam pasir untuk merelaksasikan diri di dalam hawa panas pasir $45-50^{\circ} \mathrm{C}$ cukup hanya dengan waktu 15 menit (Gambar 4).

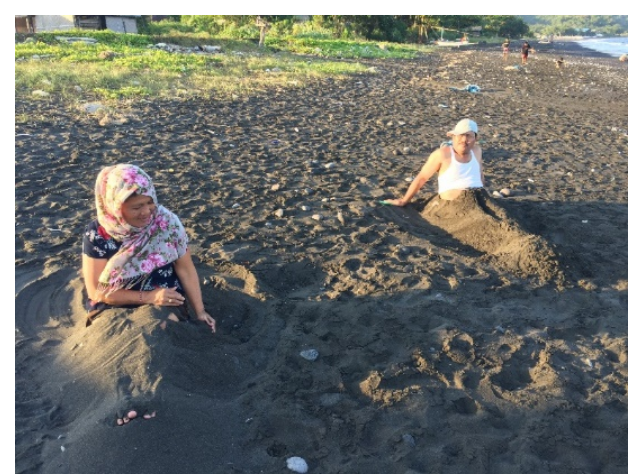

Gambar 4. Ilustrasi Menimbun Badan di Dalam Pasir (Dokumentasi Pribadi) 


\subsubsection{Rencana Sirkulasi}

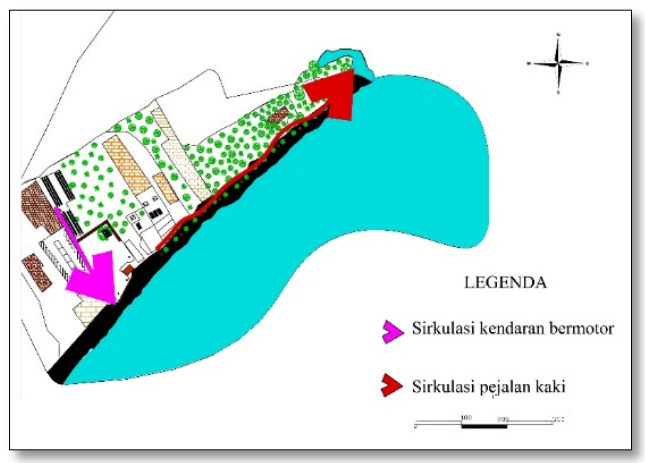

Gambar 5. Rencana Sirkulasi

Pola sirkulasi yang di adopsi yaitu pola sirkulasi linear dimana wisatawan masuk dan keluar melalui pintu yang sama. Wisatawan masuk melalui pintu utama yang berada di sebelah utara yang kemudian memasuki DTW, di dalam DTW wisatawan bebas melangkah kemanapun dan ketika wisatawan sudah selesai berkeliling wisatawan akan berjalan keluar melalui jalan yang sama pada saat memasuki DTW.

3.7.3. Rencana Vegetasi

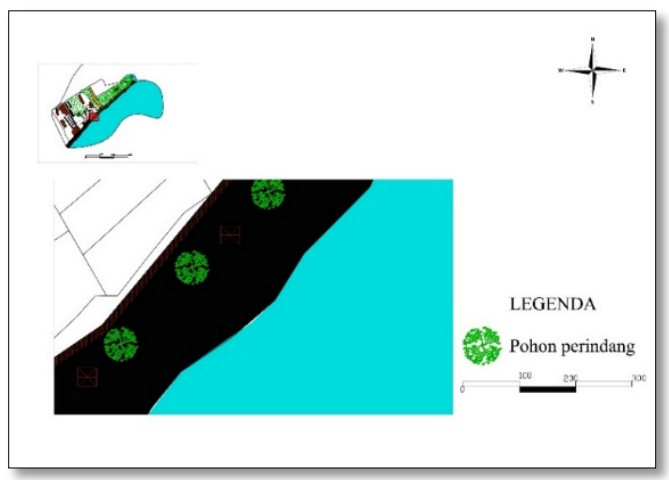

Gambar 6. Rencana Vegetasi

Vegetasi yang akan di tanam di sekitar DTW yaitu pohon perindang yang berfungsi sebagai tanaman peneduh. Tanaman waru merupakan tanaman yang dapat hidup di daerah pesisir dan tanaman ketapang merupakan tanaman yang ideal sebagai tanaman peneduh karena tajuknya yang lebar. Tidak banyak tanaman yang di gunakan selain tanaman yang sudah ada karena ingin memanfaatkan tanaman yang sudah tumbuh di sekitar DTW (Gambar 7).
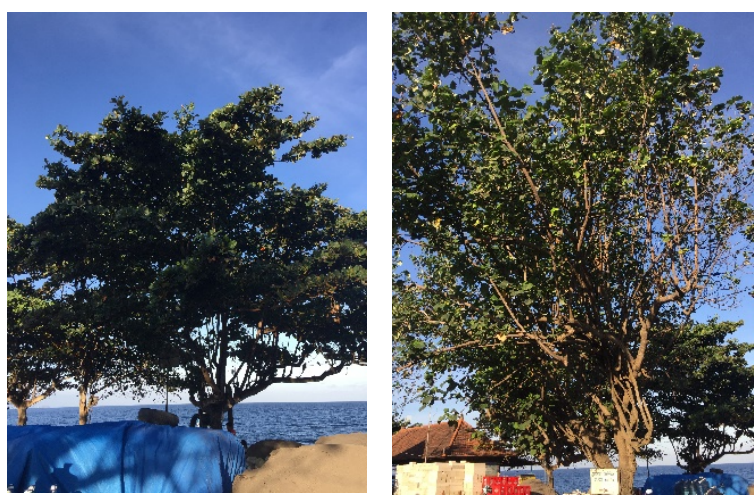

Gambar 7. Tanaman Yang Akan Digunakan Di Sekitar DTW (Dokumentasi Pribadi) Keterangan: A: Pohon Ketapang Yang Akan Digunakan Di Sekitar DTW B: Pohon Waru Yang Akan Digunakan Di Sekitar DTW 


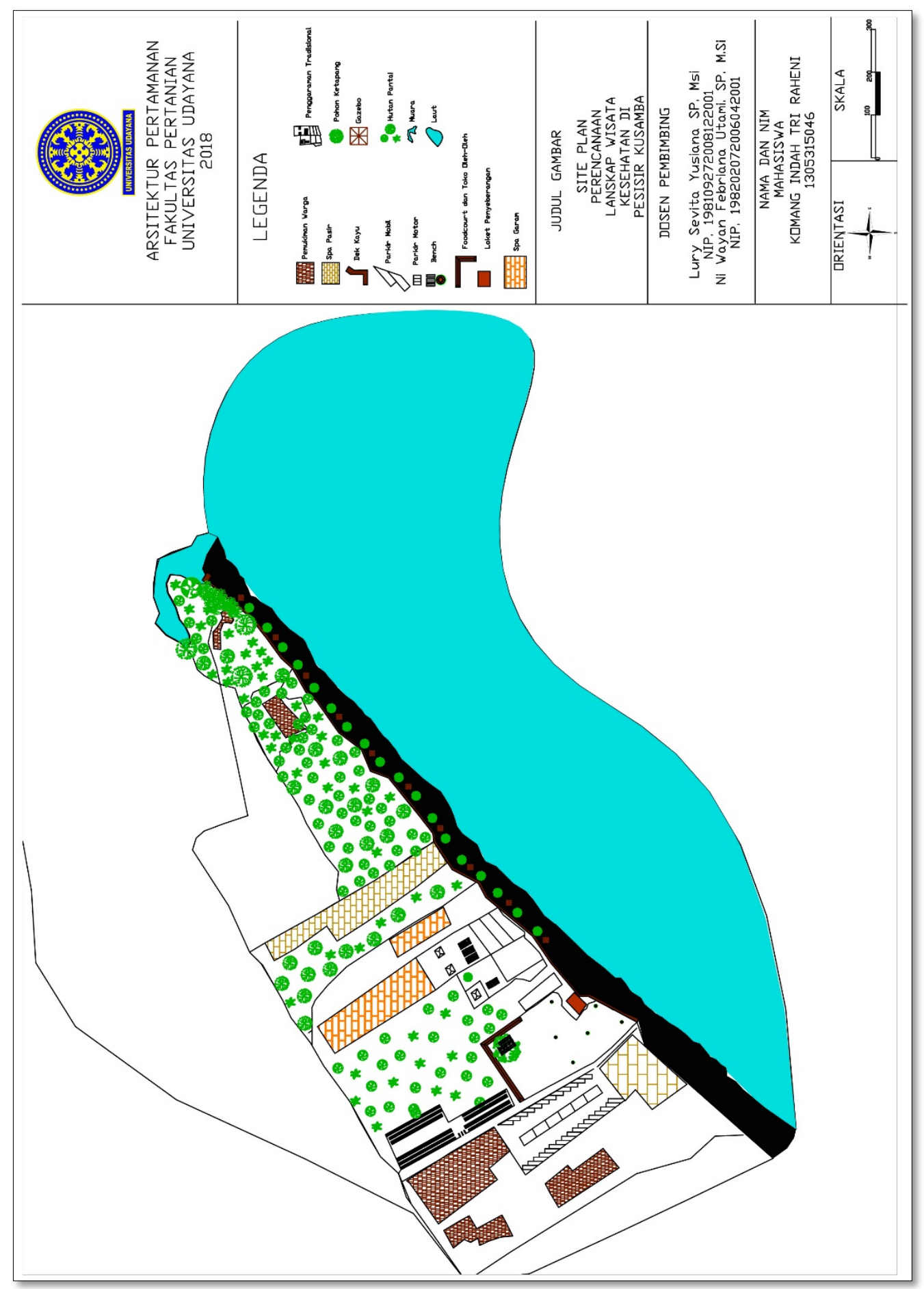

Gambar 8.Site Plan Lanskap WIsata Kesehatan di Pesisir Kusamba

Hasil akhir dari Perencanaan Lanskap Wisata Kesehatan Pesisir Kusamba, Desa Kusamba, Kecamatan Dawan,Kabupaten Klungkung yaitu site plan perencanaan wisata kesehatan di pesisir Kusamba. Wisatawan yang datang akan masuk melalui pintu utama yang juga merupakan pintu keluar dari DTW, kemudian wisatawan akan memasuki ruang inti untuk mengeksplorasi pantai menuju ke tempat tujuan seperti ke tempat-tempat terapi yang sudah di tentukan lokasinya, mengunjungi penggaraman tradisional atau sekedar duduk mengobrol di gazebo-gazebo yang telah di sediakan di pesisir pantai. Setelah mengeksplorasi pantai wisatawan akan kembali menuju pintu keluar dan melewati beberapa komplek pertokoan seperti 
foodcourt dan toko oleh-oleh. Foodcourt menjual berbagai olahan makanan khas desa Kusamba dan khas kabupaten Klungkung dan toko oleh-oleh menjual berbagai cindera mata khas desa Kusamba seperti garam tradisional yang sudah dikemas agar dapat menarik perhatian pembeli. Selanjutnya wisatawan akan kembali menuju ruang penerimaan untuk bersiap meninggalkan DTW.

\section{Simpulan dan Saran}

\subsection{Simpulan}

Berdasarkan hasil penelitian dapat ditarik simpulan yaitu potensi-potensi wisata yang terdapat di pesisir kusamba yaitu aktivitas penggaraman tradisional dan potensi alami berupa-pasir hitam yang dapat dimanfaatkan sebagai DTW khususnya wisata kesehatan. Selain itu potensi lainnya yang dapat dimanfaatkan yaitu garam tradisional yang dapat dijadikan untuk spa garam dan pasir hitam yang dapat dimanfaatkan untuk terapi pasir. Bentuk perencanaan lanskap yang diterapkan di Pesisir Kusamba adalah perencanaan lanskap wisata kesehatan yang memanfaatkan sumber daya yang ada di pesisir Kusamba seperti pemanfaatan pasir dan kerikil pantai serta garam tradisional untuk terapi (spa). Konsep yang diterapkan di perencanaan pesisir Kusamba yaitu eksplorasi dan relaksasi pantai dimana wisatawan atau pengunjung yang datang akan melakukan berbagai kegiatan seperti melihat-lihat pembuatan garam tradisional, dan sekaligus merelaksasikan tubuh dengan berjalan - jalan diatas kerikil pantai, melakukan rendam garam laut, serta terapi pasir hitam.

\subsection{Saran}

Berdasarkan simpulan di atas, dapat disarankan untuk melakukan penelitian lanjutan mengenai pengembangan wisata alam Kusamba. Hal ini dilakukan karena Kusamba memiliki hutan pantai yang sangat potensial untuk dijadikan obyek wisata alam.

\section{Daftar Pustaka}

Dharma, A. (2018). Dalam Pasir Hitam Kawasan Pantai Bali Utara Jadi Terapi Kesehatan. Di akses di www.nusabali.com tanggal 1 Maret 2018.

Hernanto B., Kwartatmono D.N. (2001). Teknologi pembuatan dan kendala produksi garam dilndonesia. Prosiding Forum Pasar Garam Indonesia.

Pemerintah Desa Kusamba. (2016). Profil Desa Kusamba. Di akses di http://www.kusamba.desa.id tanggal 28 Oktober 2016

Simonds, J.O. (2006). Landscape Architecture: A Manual of Environmental Planning and Design. United States of America. The McGraw-Hill Book Companies Inc. 396 halaman. 